\title{
Epidermomycosis at the Avicenne Military Hospital in Marrakech: 6- Year Review
}

\author{
Beddou $\mathrm{G}^{{ }^{*}}$, SKALI $\mathrm{H}^{1}$, El Mezouari $\mathrm{E}^{1}$, Hocar $\mathrm{O}^{2}$, Akhdari $\mathrm{N}^{2}$, Amal S2, Moutaj $\mathrm{R}^{1}$ \\ ${ }^{1}$ Parasitology-Mycology Service, Avicenne Military Hospital, Marrakech, Morocco \\ ${ }^{2}$ Department of dermatology, Mohamed VI university hospital, Marrakech, Morocco
}

DOI: $10.36348 /$ sjpm.2020.v05i02.010

| Received: 05.02.2020 | Accepted: 13.02.2020 | Published: 20.02.2020

*Corresponding author: Beddou Ghita

\section{Abstract}

Introduction: Epidermomycoses are superficial yeast infections that affect the epidermis outside the intertrigo. The aim of our work is to draw up a clinico-epidemiological profile of epidermomycoses diagnosed in the mycology parasitology laboratory of the Avicenne military hospital in Marrakech. Materials and methods: This is a retrospective study carried out over a period of 6 years (January 2013 to December 2018) including all the cases of epidermomycosis diagnosed. After collecting clinical information, a direct examination of the samples is carried out before culture on Sabouraud media with incubation at $27^{\circ} \mathrm{C}$. The identification of the identity was based on the speed of growth, macroscopic aspects and microscopic colonies. The identification of yeasts was based on the filamentation and assimilation of sugars test: Api 20C. Results: Epidermomycosis was confirmed in 108 cases or $57 \%$ compared to all of the samples examined. The sex ratio $\mathrm{M} / \mathrm{F}$ is 0.74 , the average age is 35.5 years. Outpatients are the majority $(86 \%)$. the prevalence of superficial dermatophyte mycoses was $81.4 \%$ followed by yeasts $(14.6 \%)$ and molds $(4 \%)$. Isolated dermatophytes are dominated by a single species Trichophyton rubrum (92\%), yeasts by Candida albicans (45\%) Conclusion: Epidermycosis is still a frequent reason for consultation in dermatology. In the face of any clinical suspicion, the mycological diagnosis remains the diagnosis of certainty and for therapeutic orientation.

Keyword: Superficial mycoses; Dermatophytes; Yeasts; Non-dermatophytic filamentous fungi.

Copyright @ 2020: This is an open-access article distributed under the terms of the Creative Commons Attribution license which permits unrestricted use, distribution, and reproduction in any medium for non-commercial use (NonCommercial, or CC-BY-NC) provided the original author and sources are credited.

\section{INTRODUCTION}

The epidermomycosis are superficial mycosis which affects the epidermis and present three clinical forms: epidermis of the hairless skin, intertrigo, and palmoplantar keratoderma. These forms are very frequent, cosmopolite affections but more frequent in tropical and subtropical zones due to their humid and hot climate. The main agents responsible for these superficial yeast infections are dermatophytes, but yeasts and saprophytic molds also remain involved. Before any suspicion of epidermomycosis, a mycological examination must be practiced in order to eliminate a differential diagnosis, to have adapted care, and to define an epidemiological profile because the prevalence of these fungi responsible for superficial mycosis varies according to regional differences, the socio-cultural habits, and immigrations.

Consequently, the aim of our work is to draw up the clinical-epidemiological profile of epidermomycosis diagnosed in the mycology parasitology laboratory of the Avicenne military hospital in Marrakech.

\section{MATERIEL ET METHODS}

This is a retrospective study carried out over a period of 6 years (from January 2013 to December 2018) including all cases of epidermomycosis diagnosed at the department of mycology parasitology of the Avicenne Military hospital in Marrakech.

The mycological analysis of the epidermis was carried out at the laboratory in the absence of any antifungal treatment or treatment stopped previously at least ten days in the case of local treatment and one month for oral one. The scaly skin lesions were collected in sterile $90 \mathrm{~mm}$ diameter Petri dishes by scraping with a scalpel blade. A direct examination of the samples in potash diluted to $30 \%$ under an optical microscope for the detection of filaments and cultures were conducted in Sabouraud's culture medium supplemented with chloramphenicol and cycloheximide (actidione*). The cultures were incubated at $27^{\circ} \mathrm{C}$ and checked daily and stored for at least five weeks before 
giving negative results. The identification of the fungus was based on the growing duration, the macroscopic appearance of colonies, the microscopic examination after staining with lactophenol blue can show the fruiting bodies and / or ornaments of the dermatophytes. The identification of yeasts was based on the filamentation and assimilation of sugars test: Api 20C aux. The diagnosis of epidermomycosis was made when the direct examination and / or culture of the samples were positive.

The data were compared using the chi-square test analysis as appropriate. The level of statistical significance was set at $\mathrm{P}<0.05$. Statistical analysis was performed using SPSS version 11.

\section{RESULTS}

The total number of samples taken for the search for epidermomycosis was 548 cases. The female gender was predominant with a sex-ratio (M / F) at 0.74 . The patients included in this study are between 12 and 75 years with an average age of 38.5 years. Out of the 548 samples taken, epidermomycosis was confirmed in 343 cases $(61 \%)$. The direct examination and culture were both positive in $80 \%$ of the cases, while in $20 \%$ of the cases the sample was positive with only direct examination or culture.

The age distribution of epidermomycosis was heterogeneous, with a maximum of involvement in the age group over 55 years except for Pityriasis Versicolor where the average age was 26 years.

Table-1: Epidemiological data

\begin{tabular}{|l|l|l|l|}
\hline Prevalence & $\begin{array}{l}\text { Sex-ratio } \\
\text { (M/F) }\end{array}$ & $\begin{array}{l}\text { Average } \\
\text { age }\end{array}$ & $\begin{array}{l}\text { Positivity } \\
\text { rate }\end{array}$ \\
\hline $80 \%$ & 0,74 & 38,5 years & $61 \%$ \\
\hline
\end{tabular}

Out of the 343 cases of epidermomycosis collected, 274 cases had localized lesions on the feet, 45 cases had hairless skin lesions and non-specific sites, 13 cases had lesions localized in hands and 11 cases had lesions on large folds. $92 \%$ of epidermomycosis cases diagnosed had an association with other superficial mycotic lesions, including feet onychomycosis.

Table-2: distribution by location

\begin{tabular}{|l|l|}
\hline Location & Rate \\
\hline Soles & 274 \\
\hline Hairless skin & 45 \\
\hline Hands & 13 \\
\hline Large folds & 11 \\
\hline
\end{tabular}

The epidermomycoses in our series were distributed as follows

At the level of the feet, 221 cases were dermatophytes whose predominant species was Trichophyton Rubrum with 198 cases, followed by Trichophyton mentagrophytes var. interdigitales with 11 cases. For yeasts, 53 cases were diagnosed with Candida sp as the predominant species in 42 cases.

In the hairless skin and non-specific site, 21 cases were dermatophytes, the predominant species of which was T. rubrum with 16 cases. For yeasts, 24 cases were diagnosed with Pityriasis versicolor with Malassezia furfur.

In the hands, 5 cases were dermatophytes, the predominant species of which was T. rubrum with 4 cases. For yeasts, 8 cases were diagnosed with Candida $\mathrm{sp}$ as the predominant species in 6 cases.

At the level of the large folds, 94 cases $(54.3 \%)$ of dermatophytes, the predominant species of which was T. rubrum with 89 cases. For yeasts, 79 cases $(45.6 \%)$ with Candida albicans 40 cases as the predominant species; are $81.4 \%$ due to dermatophytes. Trichophyton Rubrum is found in $90 \%$ of cases in our cultures followed by Trichophyton mentagrophytes var. interdigitales at 5\%. Yeasts are responsible for $14.6 \%$ of cases. And $80 \%$ of Candida Albicans, while Malassezia is the only genus responsible for pityriasis versicolor.

Table-3: distribution of dermatophytes according to location

\begin{tabular}{|l|l|l|}
\hline Location & Trichophyton rubrum & Trichophyton mantagrophytes \\
\hline Soles & 198 & 11 \\
\hline Hairless skin & 16 & - \\
\hline Hands & 4 & - \\
\hline Large folds & 89 & - \\
\hline
\end{tabular}

Table-4: distribution of yeasts by location

\begin{tabular}{|l|l|l|l|}
\hline Location & Candida sp & Candida albicans & Malassezia furfur \\
\hline Soles & 42 & - & - \\
\hline Hairless skin & - & - & 24 \\
\hline Hands & 6 & - & - \\
\hline Large folds & - & 40 & - \\
\hline
\end{tabular}




\section{DISCUSSION}

Morocco is an intertropical African country where superficial yeast infection remains frequent. Thus, a good knowledge of the epidemiology of these superficial yeast infections will be important in the management of the diagnosis and treatment of these yeast infections. Hence the importance of identifying the fungal agents of superficial yeast infection in this region. Thus, the data relating to all superficial mycosis diagnosed at the laboratory during the period from January 2013 to December 2018 were used. From these data, a $34.2 \%$ prevalence of superficial yeast infection was found. In addition, this prevalence has remained almost constant if one considers its evolution according to the years of study varying between 29 and $38.4 \%$ (laboratory data). This is a high prevalence if one considers that 20 to $25 \%$ of the world population would suffer from superficial yeast infections but with, however, an evolutionary tendency [1]. Elsewhere in Africa, in a Tunisian study, Chaker et al. had obtained a result superior to ours with $53.7 \%$ of superficial mycosis [2] while in another intertropical zone a prevalence of 50.6\% was obtained in Brazil [3].

In Europe, more particularly in Malta, France, and Turkey, prevalence rates of $32 \%, 63.1 \%$, and $70 \%$ respectively were obtained [4-6]. That of Malta is close to our result while those obtained in the two other European countries are much higher than ours. This seems contrary to observations which stipulate that in intertropical zones, due to their hot and humid climate, superficial yeast infections are more frequent than in temperate zones [7]. However, these values found in these two countries could, on the one hand, be explained by the important migratory phenomena in these two countries which are among the European countries which receive the most immigrants, African in particular and, on the other hand, by the socioeconomic conditions in these countries far ahead compared to ours in development. Indeed, mycoses remain very little known to the population in subSaharan Africa where they only rarely consult. However, whatever the geographical area, the agents of superficial yeast infections most frequently found in decreasing order are dermatophytes, yeasts, and molds. In Asia, in China [8] being the largest population in the continent, the prevalence of epidermomycosis remains low compared to our series with a rate of $20.7 \%$. concerning the infectious agent, in our series the Trichophyton Rubrum is found in $90 \%$ which joins the series reported in Malta (34.5\%) [4], Turkey (68\%) [6], Greece (48\%) [9] and Senegal (52.8\%) [10 whereas in China [8] Tinea ungium was the most frequent agent (28.5\%) and in Tunisia [2] Tinea rubrum was the most frequent $(74.5 \%)$.

\section{CONCLUSION}

Our study shows that the fungal agents fungi in Marrakech (Morocco) are dermatophytes. Their infections are more common in women than men. However, the distribution of these agents of superficial fungi varies according to age since dermatophytes are mostly found in young adults. Yeast agents of superficial yeast infection vary according to age since dermatophytes are mainly found in young adults. yeasts which are more common in young adults while molds are more common in older adults and the elderly. Finally, these epidemiological data should allow better diagnostic and therapeutic management of superficial yeast infections caused by these fungi.

\section{REFFERENCE}

1. Ameen, M. (2010). Epidemiology of superficial fungal infections. Clinics in dermatology, 28(2), 197-201.

2. Chaker, E., H'mida, S., Sfar, Z., Souissi, R., \& Kamoun, M. R. (1987). Bilan des mycoses superficielles rencontrées à l'hôpital Habib Thameur de Tunis. Ann Soc Belge Méd Trop, 67, 283-90.

3. Chiacchio, N. D., Madeira, C. L., Humaire, C. R., Silva, C. S., Fernandes, L. H. G., \& Reis, A. L. D. (2014). Superficial mycoses at the Hospital do Servidor Público Municipal de São Paulo between 2005 and 2011. Anais brasileiros de dermatologia, 89(1), 67-71.

4. Faure-Cognet, O., Fricker-Hidalgo, H., Pelloux, H., \& Leccia, M. T. (2016). Superficial fungal infections in a French teaching hospital in Grenoble area: retrospective study on 5470 samples from 2001 to 2011. Mycopathologia, 181(1-2), 5966.

5. Koksal, F., Er, E., \& Samasti, M. (2009). Causative agents of superficial mycoses in Istanbul, Turkey: retrospective study. Mycopathologia, 168(3), 117123.

6. Vella Zahra, L., Gatt, P., Boffa, M. J., Borg, E., Mifsud, E., Scerri, L., ... \& Pace, J. L. (2003). Characteristics of superficial mycoses in Malta. International journal of dermatology, 42(4), 265-271.

7. Simonnet, C., Berger, F., Gantier., J-C. (2011). Epidemiology of superficial fungal diseases in French Guiana: a three-year retrospective analysis. Med Mycol, 49:608-11.

8. Wenying, C., Changming, L., Xiqing, L., Junmin, Z., Ping, Z., Liyan, X.(2016). Epidemiology of superficial fungal infections in Guangdong, Southern China: a retrospective study from 2004 to 2014. Mycopathologia, 181(5-6):387-95.

9. Sofia, Maraki, A. (2007). 7-year survey of dermatophytoses in Crete, Greece Mycoses, 50, 481-484

10. Cai, W., Lu, C., Li, X., Zhang, J., Zhan, P., Xi, L., ... \& Yu, X. (2016). Epidemiology of superficial fungal infections in Guangdong, southern China: a retrospective study from 2004 to 2014. Mycopathologia, 181(5-6), 387-395. 